\title{
The Role of Endogenous Cortisol in Neuroendocrine Studies
}

We read with interest the study by Meltzer and colleagues (Meltzer et al. 2001) examining the cortisol response to apomorphine. The authors demonstrated a blunted cortisol and growth hormone (GH) but not prolactin (PRL) response to apomorphine in patients with schizophrenia. In the study, cortisol, PRL, and GH are used as indirect measures of central dopamine neurotransmission. There are, however, difficulties inherent in such paradigms. It has been demonstrated that corticosteroids inhibit GH but not PRL release directly at the pituitary level, thereby potentially blunting the $\mathrm{GH}$ response to all provoking agents including apomorphine (Watson et al. 2000). This is of particular relevance in studies in schizophrenia, a condition associated with dysfunction of the hypothalamic-pituitaryadrenal (HPA) axis (Lammers et al. 1995). Indeed, in the study by Meltzer and colleagues, baseline cortisol levels are higher in schizophrenic subjects than in controls. The authors state that the results provide further evidence of dopamine dysfunction in schizophrenia. We suggest that these results may, however, reflect disorder of the HPA axis. We further suggest that all studies in which neurotransmitter function is inferred from pi- tuitary hormone measures must measure corticosteroids as a potential confounding co-variate.

$$
\begin{array}{r}
\text { Stuart Watson, M.R.C.Psych. } \\
\text { Allan M. Young, M.Phil., Ph.D., M.R.C.Psych. } \\
\text { University of Newcastle } \\
\text { School of Neurosciences and Psychiatry } \\
\text { Newcastle upon Tyne, UK }
\end{array}
$$

\section{REFERENCES}

Lammers CH, Garcia-Borreguero D, Schmider J, Gotthardt V, Dettling M, Molsberf F, Heuser IJ. (1995): Combined dexamethasone/corticotropin-releasing hormone test in patients with schizophrenia and in normal controls: II. Biol Psychiatry 38:803-807

Meltzer H, Myung A, Jayathilake K (2001): The blunted plasma cortisol response to apomorphine and its relationship to treatment response in patients with schizophrenia. Neuropsychopharmacology 24:278-290

Watson S, Porter RJ, Young AH (2000): The effects of hydrocortisone on the pituitary response to growth hormone releasing hormone. Psychopharmacology 152:40-46

${ }^{2}$ Refers to PII S0893-133X(00)00201-3 